\title{
THE EFFECT OF ALKALI TREATMENT ON IMPROVING THE MECHANICAL PROPERTIES OF RAMIE (BOEHMERIA NIVEA), SUGAR PALM (ARENGA PINNATA), AND COIR (COCOS NUCIFERA) FIBERS
}

\author{
Irwan Suriaman ${ }^{1,2,}$, Jooned Hendrarsakti ${ }^{1}$, Yati Mardiyati ${ }^{1}$, and Ari Darmawan Pasek ${ }^{1}$ \\ ${ }^{1}$ Faculty of Mechanical and Aerospace Engineering, Institut Teknologi Bandung (ITB), Bandung, Indonesia \\ ${ }^{2}$ Faculty of Mechanical, Wastukancana College of Technology, Purwakarta, Indonesia, e-mail: \\ irwan_suriaman@yahoo.co.id
}

Received Date: May 27, 2020; Revised Date: February 18, 2021; Acceptance Date: April 29, 2021

\begin{abstract}
In line with economic growth, material requirements in the industrial sector will increase. Industries are required to use materials that are safe for human health, environmentally friendly and utilize local raw materials. Currently, industries in general still use synthetic materials based on petroleum residues that contain many hazardous chemicals. Therefore, natural fiber has the potential to be used as a substitute for synthetic materials, especially in Indonesia which is rich in natural fibers resources. This will have an impact on the socio-economy of the local community so that it can grow the rural economic sector. Natural fibers have high economic value that can be used for various raw material needs for strategic industries. A good natural fiber processing mechanism will produce products that can be marketed globally with guaranteed product quality. This research analyzes the effect of alkali treatment of ramie, sugar palm and coir fiber on the increase in mechanical properties of the fiber. The mechanical properties were analyzed through tensile strength testing of single fiber according to ASTM D3822 standard using a textechno favigraph machine. In addition, this research is supported by data from thermogravimetric analysis (TGA), Fourier-transform infrared spectroscopy (FTIR), and scanning electron microscopy (SEM). The results showed that the fibers that had been given an alkali treatment had better mechanical properties compared to untreated fibers. Increased tensile strength of fibers was observec after being treated with alkali for ramie $81 \%$, sugar palm $52 \%$ and coir $56 \%$. The advantage of this alkaline treatment method is that no heating is involved and the treatment procedures are more practical compared to other methods.
\end{abstract}

Keywords: Morphology, Natural fibers, Tensile strength, Treated, Untreated

\section{Introduction}

Currently, the industrial sector requires material to be processed easily, biodegradable, environmentally friendly, and with low-cost production processes [1, 2, 3, 4]. The utilization of such material will benefit companies and have a positive impact on the surrounding environment $[5,6$, ]. Currently, industries do not optimally utilize raw materials from natural fibers [7, 8]. Biofiber is a raw material that has not been managed professionally. As such, the production of fibers requires a complicated and long process and its prices are unstable $[5,9,10,11]$. 
Indonesia has an enormous potential of natural fibers due to its tropical climate and a large plantable area [1]. The estimated annual yield of Indonesia's natural fibers are around fifteen million tons from all regions of the country. In fact, domestic and international industries have widely used Indonesia's natural fibers. Currently, researchers are developing several types of Indonesian natural fibers into potential industrial raw materials, such as ramie, palm sugar and coir fiber [12]. The natural fibers still need to be improved in terms of their mechanical properties, water resistance, and production process $[13,14]$. Various methods have been used in producing natural fibers for industrial purposes including alkaline processes $[15,16,17,18]$. These alkali processes have been used for a variety of fibers such as hemp, jute, coir, and ramie but still involve heat treatment and excessive use of many chemicals [14, 19].

Natural fibers have been widely used in various industrial fields [18, 20]. The implementation of composite materials is a very rapid development in the various automotive, medical, manufacturing and aircraft industries [17]. The reason investors use natural fibers in this industry is due to its low price and shorter processing stages. In addition, natural fibers provide a healthier environmental impact because greenhouse pollution can be reduced $[14,15]$. Another reason is that natural fibers have good mechanical properties, abundant supply, heat resistant, resistant to insects, has good water absorption, abrasion resistance and easy to modify their chemical structure $[17,18]$.

The potential of natural fibers as the main raw material for the industry needs to be supported by researchers in order to produce quality products. Raw materials from natural fibers in Indonesia are expected to be a substitute for synthetic fibers that are currently primarily used in the industrial world. This research aims to analyze the effect of alkali treatment on increasing the mechanical properties of ramie, sugar palm and coir fibers. The results of this research are expected to provide knowledge related to effective raw material processing mechanisms to improve the mechanical properties of fibers. This offers savings on production costs and produces high-value products. In addition, this research offers considerations for the industry sector related to the methods used in the processing of natural fibers by presenting data related to tensile strength, Fourier-transform infrared spectroscopy (FTIR), thermogravimetric analysis (TGA) and electron microscopy (SEM).

\section{Materials and Methods}

This study used natural fibers of plants from the mountainous region of Garut with $7^{0} 45^{\text {' }} \mathrm{S}$ latitude; $108^{0} 7^{\prime} \mathrm{E}$ longitude, West Java, Indonesia. The plants used in this study are ramie as shown in Figure 1(A), sugar palm (Figure 1(B)), and coconut tree (Figure 1(C)). Ramie is a cambium plant with a height of about $2 \mathrm{~m}$, which can be harvested at the age of 2 to 5 months. Palm fiber and coconut trees are types of palms that have a single trunk that can reach a height of more than $5 \mathrm{~m}$ and an age of more than ten years. These three natural fibers thrive throughout Indonesia. Fiber crops do not require special conditions related to climate and soil fertility, so they are very easily cultivated by farmers [19]. The production of ramie fiber from fertile agricultural land produces an average of 2 tonnes per hectare, whereas for coir and sugar palm, the resulting fiber production is smaller depending on the fertility of the plant. 

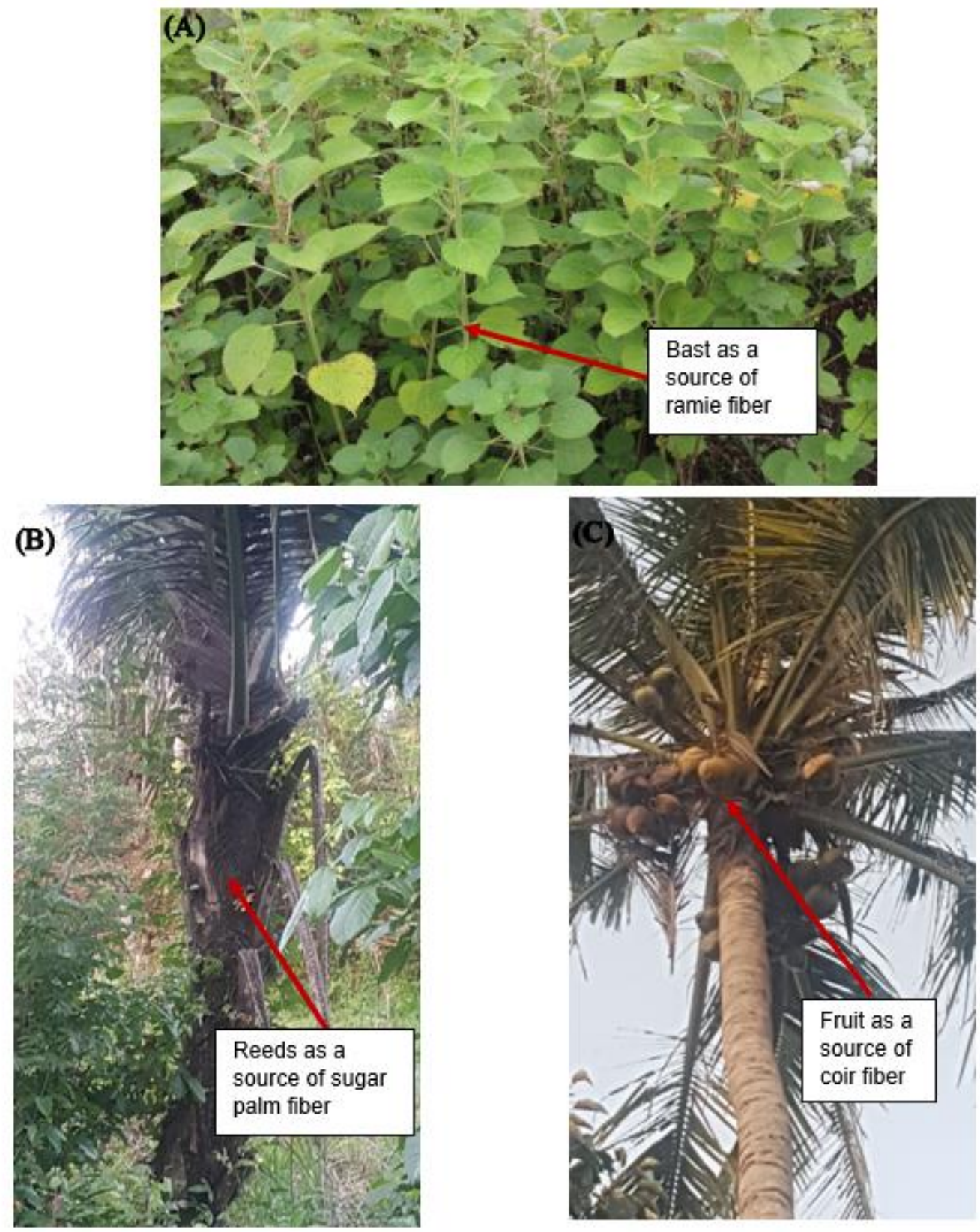

Figure 1. Plant as sources of natural fibers: (A) ramie (Boehmeria nivea); (B) sugar palm (Arenga pinnata); (C) coconut tree (Cocos nucifera)

Ramie fiber comes from the bast, sugar palm fiber from the reeds whereas coconut fiber originates from the coconut coir which is dried in the sun until the fiber has a moisture content of about $10-14 \%$. The natural fibers of ramie are shown in Figure 2(A), sugar palm fibers in Figure 2(B) and coir fiber in Figure 2(C). The natural fibers in Figure 2 are the raw material that was collected from the plants and have not been treated with chemicals. Then the three types of fiber were measured for their moisture content, if they were still high, then they were dried again in the sun. Furthermore, each fiber is given alkali $(\mathrm{NaOH})$ treatment at levels of $0-5 \%$. 

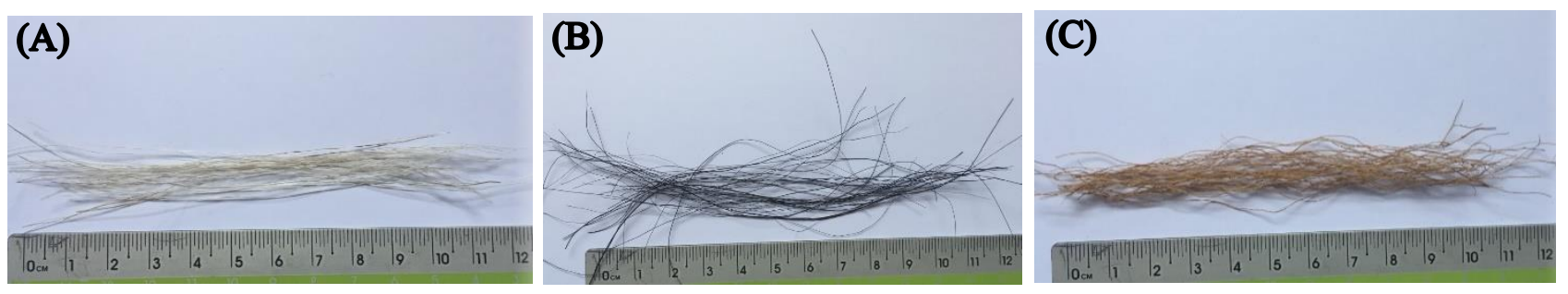

Figure 2. Fiber of raw material: (A) ramie; (B) sugar palm; (C) coir

\section{Sample Treatment}

The ramie fiber, palm fiber, and coir fiber were divided into two batches, i.e., one untreated batch and one batch in which the fibers were given an alkali treatment with sodium hydroxide $(\mathrm{NaOH})$ at concentrations of $1-5 \%$ with a fiber weight of $0.1 \mathrm{~kg}$ each. The alkali treatment was carried out at room temperature of around $28{ }^{\circ} \mathrm{C}$ with humidity of $56 \%$ for 2 hours, using demineralized water with a PH of 6 . After the treatment, the fibers were washed with water at PH 6 and subsequently dried naturally with sunlight $[16,21,22]$.

The test sample can be described using the following codes: untreated ramie (RA0); 1-5\% treated ramie (RA1-RA5, respectively); untreated sugar palm (IJ0); 1-5\% treated sugar palm (IJ1IJ5, respectively); untreated for coir fiber (SK0); 1-5\% treated coir fiber (SK1-SK5, respectively).

\section{Tensile Strength}

The tensile strength of the untreated and treated fibers was tested using a textechno favigraph machine as shown in Figure 3. This test was carried out at the Center for Textile (CFT) Bandung, West Java, based on ASTM D3822 standards. The test was carried out for single fibers with were $10 \mathrm{~cm}$ and a diameter range of $0.1-0.8 \mathrm{~mm}$. The gauge length was $10 \mathrm{~mm}$ with a speed of $20 \mathrm{~mm} / \mathrm{min}$ at room temperature conditions around $26{ }^{\circ} \mathrm{C}$ with $\mathrm{RH} 56$ with 12 repetitions for each sample.

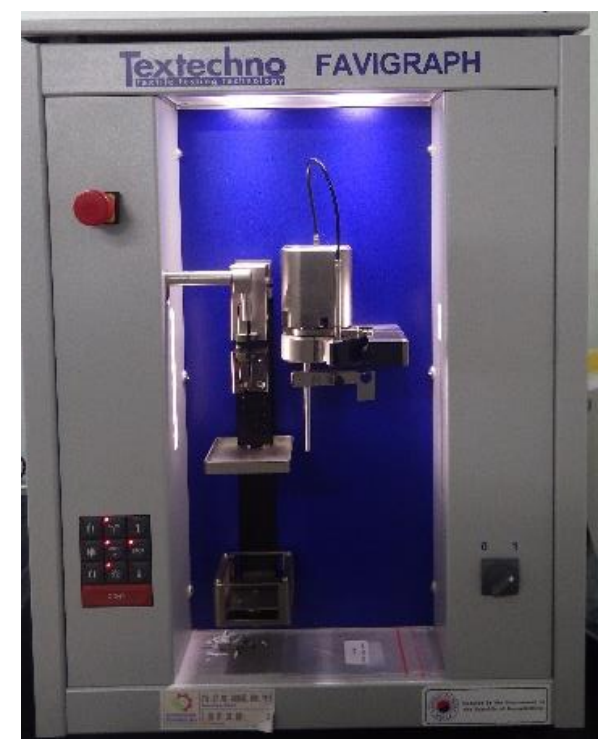

Figure 3. Favigraph textechno machine 


\section{Thermogravimetric Analysis}

TGA analysis was conducted for untreated materials and fibers given alkali treatment to analyze changes in sample mass using continuous heat treatment. This analysis was conducted using TGHDSC thermogravimetric analyzer (TGA) in the chemical engineering laboratories of the Bandung Institute of Technology (ITB). Each sample was cut into small pieces and then coated with alumina crucibles. Each sample was given heat treatment at a temperature range of $30{ }^{\circ} \mathrm{C}$ up to $500{ }^{\circ} \mathrm{C}$ with a heating rate of $10 \mathrm{~K} / \mathrm{min}$ without nitrogen.

\section{Fourier-Transform Infrared Spectroscopy}

FTIR analysis was carried out for untreated and treated fibers to confirm the lignocellulosic (cellulose, hemicellulose, and lignin) content. This was tested quantitatively through the ChessonDatta method and analyzed using the Shimadzu Prestige 21 Fourier-transform infrared spectrophotometer at the analytical chemistry laboratory of the Faculty of Mathematics and Natural Sciences, Bandung Institute of Technology (ITB). Each sample was cut into small pieces, mixed with $\mathrm{KBr}$, mashed, and then shaped like a pellet. The tests were carried out in the wave range of $500-4500 \mathrm{~cm}^{-1}$.

\section{Scanning Electron Microscopy}

The morphology of untreated and treated fibers for $3 \%$ alkali $(\mathrm{NaOH})$ treatment was analyzed in the cross-section using the JEOL JSM-6510 scanning electron microscope (SEM), conducted at the Center for Textiles (BBT), Bandung, West Java. Each sample was first cut to a size of $1 \mathrm{~cm}$, affixed to an aluminum plate and then given a layer of gold $(\mathrm{Au})$ using a JEOL JEC-3000FC sputter coater.

\section{Statistics Analysis}

The results of tensile strength for statistical analysis used SPSS statistics version 25 . The calculation used analysis of variance (ANOVA) with $p$-values for a significant factor $\mathrm{p}=0.05$.

\section{Result and Discussion}

The raw materials used in this research consisted of ramie (RA0); sugar palm (IJ0) and coir (SK0) fiber. Its characteristics, mechanical properties, and chemical element content are shown in Table 1. The lignocellulosic (cellulose, hemicellulose, and lignin) contents were obtained from ChessonDatta tests conducted at the green polymer laboratory of Institut Teknologi Bandung (ITB).

\section{Table 1. Comparative Properties and Chemical Composition of the Raw Material of} Ramie, Sugar Palm and Coir Fibers

\begin{tabular}{|c|c|c|c|c|c|c|c|c|c|}
\hline \multirow[t]{2}{*}{ Natural Fibers } & \multirow{2}{*}{$\begin{array}{l}\text { Density } \\
\left(\mathrm{g} / \mathrm{cm}^{3}\right)\end{array}$} & \multirow{2}{*}{$\begin{array}{l}\text { Diameter } \\
(\mu \mathrm{m})\end{array}$} & \multirow{2}{*}{$\begin{array}{l}\text { Tensile } \\
\text { Strength } \\
\text { (MPa) }\end{array}$} & \multirow{2}{*}{$\begin{array}{c}\text { Young's } \\
\text { Modulus } \\
\text { (GPa) }\end{array}$} & \multirow{2}{*}{$\begin{array}{c}\text { Elongation } \\
\text { at Break } \\
(\%)\end{array}$} & \multicolumn{4}{|c|}{ Chemical Composition (wt\%) } \\
\hline & & & & & & Cellulose & Hemicellulose & Lignin & Pectin \\
\hline Ramie (RA0) & $1.45-1.65$ & $76-112$ & 715 & 86 & 4 & $68-78$ & $15-19$ & $1-5$ & $1-3$ \\
\hline Sugar palm (IJ0) & $1.28-1.43$ & $97-225$ & 287 & 12 & 6 & $38-41$ & $20-22$ & $29-35$ & $1-7$ \\
\hline Coir (SK0) & $1.34-1.48$ & $125-356$ & 159 & 5 & 21 & $34-45$ & $9-13$ & $25-39$ & $4-6$ \\
\hline
\end{tabular}


Table 1 shows that ramie fiber has the highest cellulose content of about $50 \%$ higher compared to sugar palm and coir fiber. The highest lignin content is found in coir fiber at around $39 \%$ and sugar palm fiber (IJ) has the highest hemicellulose content of around $22 \%$. The highest tensile strength test results on ramie fiber (RA) around $715 \mathrm{MPa}$ with a difference of about $60 \%$ of coir fiber (SK). Of the three fibers, ramie fiber has the finest diameter below $100 \mu \mathrm{m}$. Moreover, the average density of the three fibers is almost the same.

The ANOVA analysis results showed that alkali treatment had a significant effect $(\mathrm{p}<0.05)$ on the tensile strength of hemp, palm and coir fibers. The concentration of alkali content in the range $(0-5 \%)$ has a significant effect $(\mathrm{p}<0.05)$ on the three types of fibers with an increase in tensile strength of more than $50 \%$ and even hemp fiber increases by about $81 \%$. This significant increase indicates that the alkaline treatment $(\mathrm{NaOH})$ on hemp, palm fiber and coconut husk is very effective in improving mechanical properties $[15,17,19,20]$.
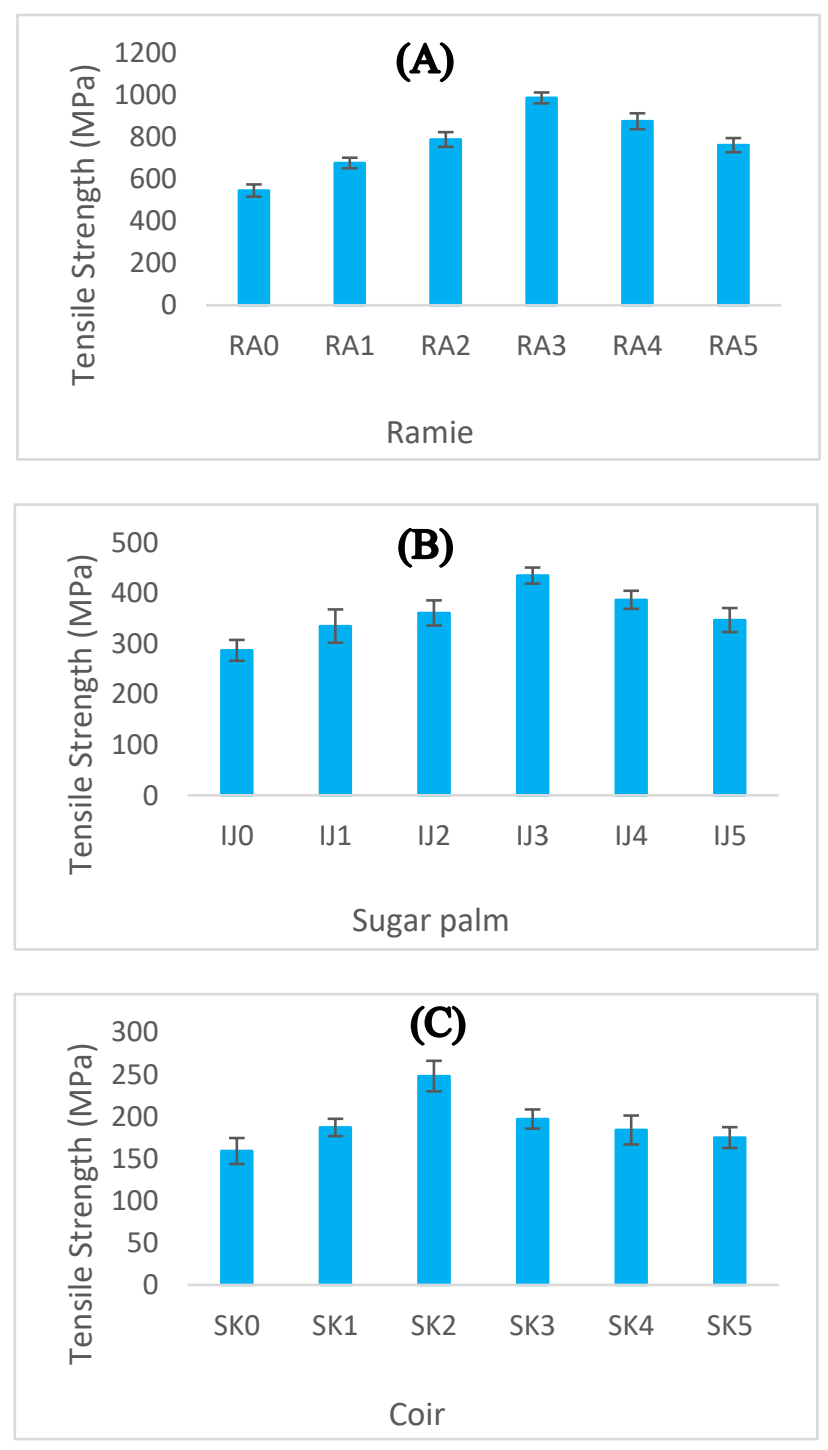

Figure 4. Tensile strength of treated and untreated fibers: (A) ramie; (B) sugar palm; (C) coir 
Figure 4 presents the tensile strength test results and shows that the alkali $(\mathrm{NaOH})$ treatment significantly changes the tensile strength of ramie, sugar palm and coir fibers. For the fiber of ramie, Figure 4(A) shows the highest tensile strength yield for the treatment of 3\% alkali or fiber type RA3 of around $987 \mathrm{MPa}$. Figure 4(B) shows that the highest tensile strength for the sugar palm fiber is also at $3 \%$ alkali or fiber IJ3, around $425 \mathrm{MPa}$. Lastly, Figure 4(C) shows that the highest tensile strength for coir fibers is at $2 \%$ alkali (SK2) with a tensile strength of $248 \mathrm{MPa}$. From the test, it appears that the increase in tensile strength occurs due to a decrease in lignin content, impurities, and gums due to the alkali treatment which can then be described in more detail from the results of the TGA, FTIR and SEM tests. However, the increase in tensile strength has an optimum point after which a significant decrease will occur [23, 24, 25].
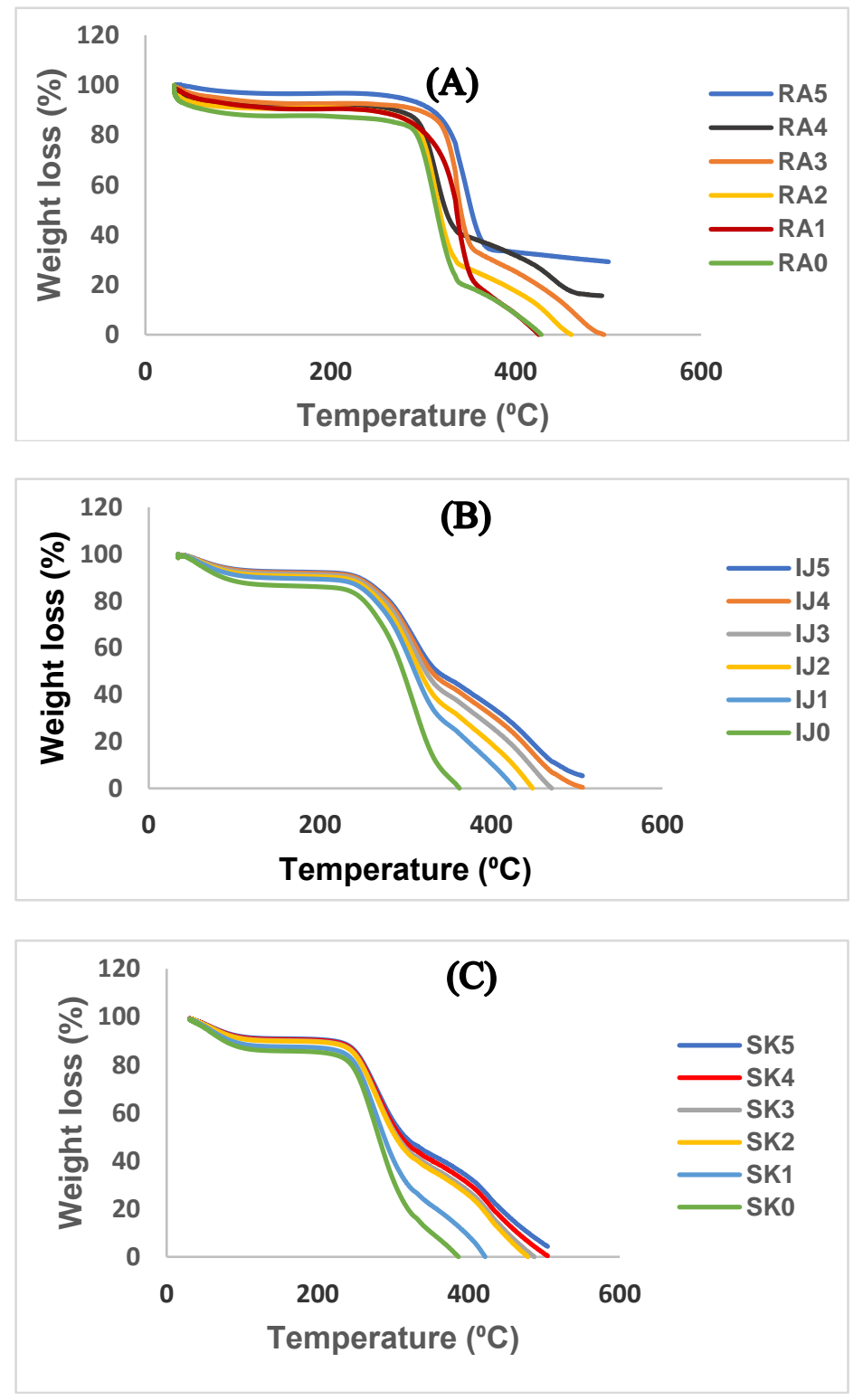

Figure 5. Thermogravimetric analysis (TGA) of treated and untreated fibers: (A) ramie; (B) sugar palm; (C) coir 
Figure 5 shows the degradation temperature curve of ramie, sugar palm, and coir fibers. Generally, the results of the TGA tests for all three fibers indicate an increase in degradation temperature directly proportional to the increase in the percentage of alkali $(\mathrm{NaOH})$ administered. At a temperature range of $0-200{ }^{\circ} \mathrm{C}$, all three fibers experience a decomposition of water content and other gas elements with a weight loss of around 20\%. For ramie fiber (Figure 5(A)), there is a significant decomposition at temperatures of 270 to $335{ }^{\circ} \mathrm{C}$ with a weight loss of about $65 \%$. Meanwhile, the sugar palm fiber (Figure 5(B)) shows significant decomposition at temperatures of 225 to $315^{\circ} \mathrm{C}$ with a weight loss of around $75 \%$. For coir fibers, Figure $5(\mathrm{C})$ shows significant decomposition at temperatures of 245 to $307^{\circ} \mathrm{C}$ with a weight loss of around $58 \%$. At the stage of significant weight loss, the primary bond damage occurs in the cellulose polymer which causes the material to change its structure. Then the material turns to ash with a weight loss of around $10 \%[13,26]$.

Figure 6 shows the results of FTIR testing of ramie, sugar palm, and coir fiber which were treated alkaline and untreated. Moreover, Table 2 compares the FTIR spectra of the fibers in the range of wavenumbers from 4000 to $500 \mathrm{~cm}^{-1}$. The results show significant differences in the alkali administration of each type of fiber. For lignocellulose spectrum of wavenumbers, the 3450$1400 \mathrm{~cm}^{-1}$ is $\mathrm{O}-\mathrm{H}$ stretching of cellulose; for $1740-1720 \mathrm{~cm}^{-1}$, this is $\mathrm{C}=\mathrm{O}$ stretching of hemicellulose; wavenumber $1635 \mathrm{~cm}^{-1}$ is $\mathrm{C}=\mathrm{O}$ stretching of lignin; the $1268 \mathrm{~cm}^{-1}$ is $\mathrm{C}-\mathrm{O}$ guaiacyl aromatic; the $1100-1005 \mathrm{~cm}^{-1}$ is C-O stretching of cellulose; for $896 \mathrm{~cm}^{-1}$ is the $\beta$-glycosidic for cellulose. From Figure 6(A) shows that the wavenumber with the highest spectrum in the range $3480-3451 \mathrm{~cm}^{-1}$ and $1077-1055 \mathrm{~cm}^{-1}$ shows O-H and C-O stretching is an indicator that the ramie fiber is rich in cellulose content. In Figure 6(B) and Figure 6(C), the highest wavenumber spectrum at $1383 \mathrm{~cm}^{-1}$ indicates the high lignin element in sugar palm and coir fibers. For the three fibers treated with alkali, the FTIR curve clearly shows an increase in cellulose content compared to untreated fibers $[15,11,27]$.

Table 2. Comparison of FTIR Spectra of Treated and Untreated Ramie, Sugar Palm, and Coir Fibers

\begin{tabular}{clrrr}
\hline \multirow{2}{*}{ Assignment } & \multicolumn{3}{c}{ Wavenumber (cm-1) } \\
\cline { 3 - 5 } & & Ramie & Sugar Palm & Coir \\
\hline & O-H Stretching & $3480-3451$ & $3461-3449$ & $3451-3449$ \\
Absorption of cellulose & C-O Stretching & $1077-1055$ & $1083-1048$ & $1045-1010$ \\
& $\beta-(1-4)$ glycosidic bond & $898-870$ & $905-885$ & $904-867$ \\
\hline $\begin{array}{c}\text { Absorption of } \\
\text { hemicellulose }\end{array}$ & $\mathrm{C}=0$ bending & $1750-1715$ & $1775-1710$ & $1765-1705$ \\
& $\mathrm{CH} 2$ bending & $1440-1425$ & $1447-1418$ & $1442-1410$ \\
\hline \multirow{2}{*}{\begin{tabular}{c} 
Absorption of lignin \\
\cline { 2 - 4 }
\end{tabular}} & $\mathrm{C}-\mathrm{O}$ bending & $1385-1360$ & 1383 & 1383 \\
& $\mathrm{C}=0$ Stretching & $1645-1638$ & $1640-1630$ & $1655-1630$ \\
\hline
\end{tabular}



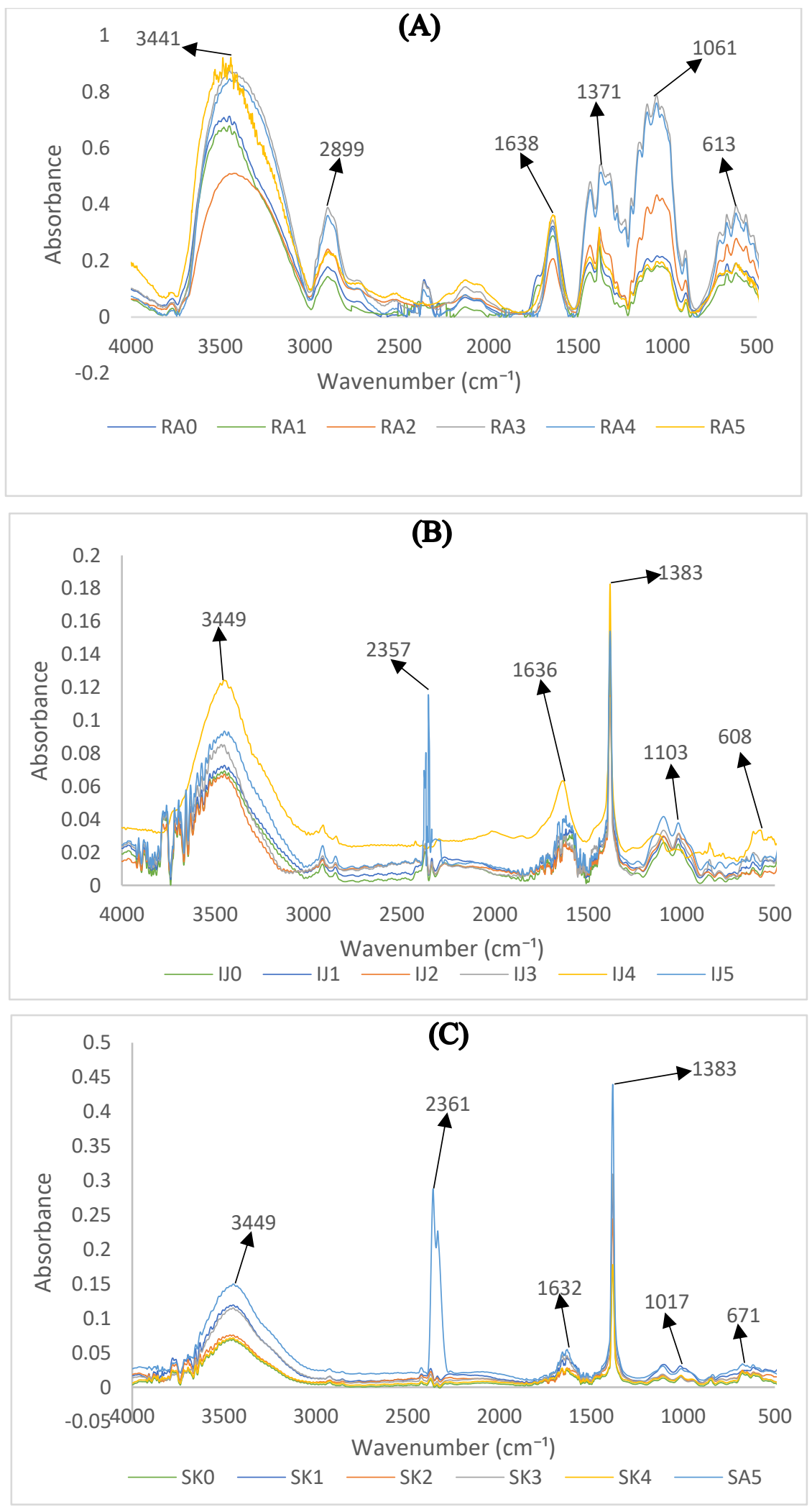

Figure 6. Fourier-transform infrared spectroscopy (FTIR) of treated and untreated fibers: (A) ramie; (B) sugar palm; (C) coir 
Figure 7 shows the morphology of untreated fibers in Figure 7(A-C), whereas Figure $7(\mathrm{D}-\mathrm{F})$ shows the morphology of fibers after $3 \% \mathrm{NaOH}$ alkaline treatment. After this treatment, the clarity of the gums with the fibers' microfibrils is more obvious for the ramie, sugar palm and coir fibers. Moreover, this treatment increased the tensile strength of the fiber, which, in turn, also increased the heat resistance of the level of degradation due to reduced lignin, gum, and other impurities. Thus, the treatment changes the morphological structure of the fibers and increases their mechanical and thermal properties up to the minimum standards as required by the industry for high-quality raw material [16, 28, 29, 30].
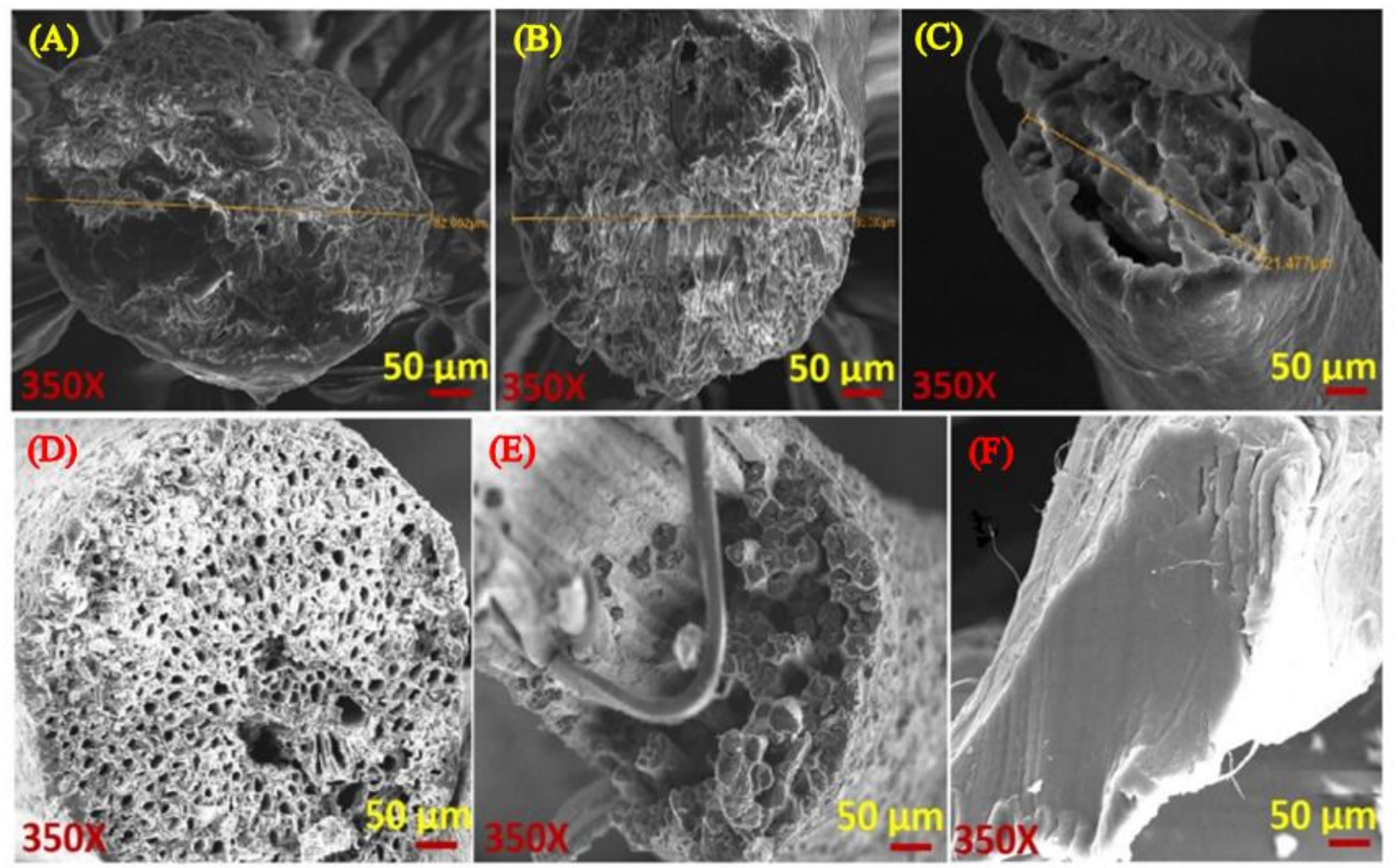

Figure 7. Scanning electron microscopy (SEM) micrographs show the morphology of fibers for untreated: (A) coir (SK0); (B) sugar palm (IJ0); (C) ramie (RA0) and treated: (D) coir (SK3); (E) sugar palm (IJ3); (F) ramie (RA3)

The alkali treatment given to the three fibers, even without heat treatment and using a small amount of sodium hydroxide, could improve their mechanical properties. In addition, the treatment led to a significant decrease in the amount of lignin and gum [28, 29, 30, 32]. It is necessary to reassess the research on alkali treatment with heat treatment or the excessive use of chemicals in the degumming process $[19,16,31]$. A consideration for alkali treatments is the region where fiber-producing plants grow as well as post-harvest fiber processing mechanisms. Each region has a different level of soil fertility, climate, and rainfall; these factors will affect the type of biological fiber that can be produced. Consequently, the alkaline treatment given will be different. Therefore, a preliminary test is needed to determine the characterization of the fibers to find the optimal alkali treatment method. 


\section{Conclusions}

The results showed an increase in tensile strength for ramie, sugar palm and coir fiber after being given an alkali $(\mathrm{NaOH})$ treatment. However, alkali treatment has an optimum, therefore, each type of fiber needs a different treatment. Tensile strength for ramie fiber was optimal for 3\% alkali treatment with a value of $987 \mathrm{MPa}$, sugar palm fiber tensile strength as optimal at 3\% alkali with a value of $435 \mathrm{MPa}$ whereas the optimum for coir fiber was at $2 \%$ with a value of $248 \mathrm{MPa}$. The alkali effect also makes a difference in the TGA curve; the study shows an increase of about 5$10 \%$ in the heat resistance of each fiber. The FTIR results clearly show the effects of alkali treatment, i.e., a decrease in the levels of lignin and gum. These findings were reinforced by the SEM results which showed a clearly visible difference in morphology of fibers before and after alkali treatment. This research is expected to be a consideration for businesses that use fiber as raw material as it offers an effective method to reduce levels of lignin and gum. As such, natural fibers will be a better raw material as it is safer and healthier.

\section{References}

[1] D.R. Adawiyah, T. Sasaki, and K. Kohyama, "Characterization of arenga starch in comparison with sago starch," Carbohydrate Polymers, Vol. 92, No. 2, pp. 2306-2313, 2013.

[2] L.G. Angelini, and S. Tavarini, "Rami (Boehmeria nivea (L.) Gaud) as a potential new fibre crop for the Mediterranean region: Growth, crop yield and fibre quality in a long-term field experiment in Central Italy," Industrial Crops and Products, Vol. 51, pp. 138-144, 2013.

[3] H.M.C. Azeredo, M.F. Rosa, L. Henrique, and C. Mattoso, "Nanocellulose in bio-based food packaging applications," Industrial Crops and Products, Vol. 97, pp. 664-671, 2017.

[4] M. Rajesh, and J. Pitchaimani, "Mechanical properties of natural fiber braided yarn woven composite: comparison with conventional yarn woven composite," Journal of Bionic Engineering, Vol. 14, No. 1, pp. 141-150, 2017.

[5] M.M. Kabir, H. Wang, K.T. Lau, and F. Cardona, "Chemical treatments on plant-based natural fiber reinforced polymer composites: An overview," Composites Part B, Vol. 43, No. 7, pp. 2883-2892, 2012.

[6] J. Ni, A. Zhu, X. Wang, Y. Xu, Z. Sun, and J. Chen, "Genetic diversity and population structure of ramie (Boehmeria nivea L.)," Industrial Crops and Products, Vol. 115, pp. 340347, 2018.

[7] S.N. Monteiro, L.A.H. Terrones, and J.R.M. D'Almeida, "Mechanical performance of coir fiber / polyester composites," Polymer Testing, Vol. 27, pp. 591-595, 2008.

[8] J.M. Yuan, and Y.R. Feng, "Effect of thermal treatment on properties of ramie fibers," Polymer Degradation and Stability, Vol. 133, pp. 303-311, 2016.

[9] S. Harish, D.P. Michael, A. Bensely, D.M. Lal, and A. Rajadurai, "Mechanical property evaluation of natural fiber coir composite," Materials Characterization, Vol. 60, No. 1, pp. 44-49, 2008.

[10] R.A. lyas, S.M. Sapuan, and M.R. Ishak, "Isolation and characterization of nanocrystalline cellulose from sugar palm fibers (Arenga Pinnata)," Carbohydrate Polymers, Vol. 181, pp. 1038-1051, 2018.

[11] M. Ramesh, K. Palanikumar, and K.H. Reddy, "Plant fiber-based bio-composites: Sustainable and renewable green materials," Renewable and Sustainable Energy Reviews, Vol. 79, pp. 558-584, 2017. 
[12] N. Ezekiel, B. Ndazi, C. Nyahumwa, and S. Karlsson, "Effect of temperature and durations of heating on coir fibers," Industrial Crops and Products, Vol. 33, No. 3, pp. 638-643, 2011.

[13] D.M. Krishnudu, D. Sreeramulu, and P.V. Reddy, "Alkali treatment effect: Mechanical, thermal, morphological, and spectroscopy studies on abutilon indicum fiber-reinforced composites alkali treatment effect: Mechanical, thermal, morphological, and spectroscopy studies on abutilon indicum fiber-reinforced composites," Journal of Natural Fibers, Vol. 17, No. 12, pp. 1-10, 2019.

[14] J. Cruz, and R. Fangueiro, "Surface modification of natural fibers: A review," Procedia Engineering, Vol. 155, pp. 285-288, 2016.

[15] R.V.S. Reddy, and D.M. Krishnudu "Alkali treatment influence on characterization of Setaria Italic (foxtail millet) fiber reinforced polymer composites using vacuum bagging," Journal of Natural Fibers, pp. 1-13, 2020. Doi: 10.1080/15440478.2020.1788494

[16] P.V. Reddy, D.M. Krishnudu, and P.R. Prasad, "A study on alkali treatment influence on prosopis juliflora fiber-reinforced epoxy composites a study on alkali treatment influence on prosopis juliflora fiber-reinforced epoxy composites," Journal of Natural Fibers, pp. 1-13, 2019. doi: 10.1080/15440478.2019.1687063

[17] P.V. Reddy, R.V.S. Reddy, J.L. Rao, D.M. Krishnudu, and P.R. Prasad, "An overview on natural fiber reinforced composites for structural and non-structural applications," Materials Today: Proceedings, 2020. doi: 10.1016/j.matpr.2020.10.523

[18] B.M. Reddy, R.M. Reddy, B.C. Mohan, P.V. Reddy, H.R. Rao, and Y.V.M. Reddy, "The effect of granite powder on mechanical, structural and water absorption characteristics of alkali treated cordia dichotoma fiber reinforced polyester composite," Polymer Testing, Vol. 91, p. 106782, 2020.

[19] S. Renouard, C. Hano, J. Doussot, J. Blondeau, and E. Lainé, "Characterization of ultrasonic impact on coir, flax and hemp fibers," Materials Letters, Vol. 129, pp. 137-141, 2014.

[20] R. Kandimalla, S. Kalita, B. Choudhury, D. Devi, D. Kalita, K. Kalita, and J. Kotoky, "Fiber from ramie plant (Boehmeria nivea): A novel suture biomaterial," Materials Science and Engineering C, Vol. 62, p. 816822, 2016.

[21] O. Nechyporchuk, M.N. Belgacem, and J. Bras, "Production of cellulose nanofibrils: A review of recent advances," Industrial Crops and Products, Vol. 93, pp. 2-25, 2016.

[22] G.R. Arpitha, and B. Yogesha, "An overview on mechanical property evaluation of natural fiber reinforced polymers," Materials Today: Proceedings, Vol. 4, No. 2, pp. 2755-2760, 2017.

[23] R.A. lyas, S.M. Sapuan, M.R. Ishak, and E.S. Zainudin, "Sugar palm nano fibrillated cellulose (Arenga pinnata) merr: Effect of cycles on their yield, physic-chemical, morphological and thermal behavior," International Journal of Biological Macromolecules, Vol. 123, pp. 379-388, 2019.

[24] C. Meng, N. Zhong, J. Hu, C. Yu, and J.N. Saddler, "The effects of metal elements on ramie fi ber oxidation degumming and the potential of using spherical bacterial cellulose for metal removal," Journal of Cleaner Production, Vol. 206, pp. 498-507, 2019.

[25] K. Oksman, Y. Aitomäki, A.P. Mathew, G. Siqueira, Q. Zhou, S. Butylina, and S. Hooshmand, "Review of the recent developments in cellulose nanocomposite processing," Composites Part A, Vol. 83, pp. 2-18, 2016.

[26] M. Rehman, D. Gang, Q. Liu, Y. Chen, B. Wang, and D. Peng, "Ramie a multipurpose crop: potential applications, constraints and improvement strategies," Industrial Crops and Products, Vol. 137, pp. 300-307, 2019. 
[27] R.M. Rowell, J.S. Han, and J.S. Rowell, "Characterization and factors effecting fiber properties," Natural Polymers an Agrofibers Composites, pp. 115-134, 2000.

[28] J. Sahari, S.M. Sapuan, E.S. Zainudin, and M.A. Maleque, "Thermo-mechanical behaviors of thermoplastic starch derived from sugar palm tree (Arenga pinnata)," Carbohydrate Polymers, Vol. 92, No. 2, pp. 1711-1716, 2013.

[29] N. Sgriccia, M.C. Hawley, and M. Misra, "Characterization of natural fiber surfaces and natural fiber composites," Vol. 39, pp. 1632-1637, 2008.

[30] B. Taalah, A. Guettala, S. Guetala, and A. Kriker, "Mechanical properties and hygroscopicity behavior of compressed earth block filled by date palm fibers," Conbuildmat, pp. 161-168, 2014.

[31] L. Yan, N. Chouw, L. Huang, and B. Kasal, "Effect of alkali treatment on microstructure and mechanical properties of coir fibres, coir fiber reinforced-polymer composites and reinforced-cementitious composites," Construction and Building Materials, Vol. 112, pp. 168-182, 2006.

[32] R.B. Yusoff, H. Takagi, and A.N. Nakagaito, "Tensile and flexural properties of polylactic acid-based hybrid green composites reinforced by kenaf, bamboo and coir fibers," Industrial Crops and Products, Vol. 94, pp. 562-573, 2016. 